\title{
Using Linked Lung Cancer Registry and Hospital Data for Guiding Health Service Improvement
}

\author{
D Roder, H You, D Baker, R Walton, B McCaughan, S Aranda and D Currow
}

\author{
Abstract \\ Objective: To use linked NSW Cancer Registry and \\ hospital lung cancer (LC) data for raising discussion \\ points on how to improve outcomes.
}

Design: Historical cohort - cases diagnosed in 2003-2007. Setting: New South Wales, Australia

Outcome Measures: Relative odds (OR) of localised disease and resection of non-small cases (NSCLC) using multiple logistic regression. Comparisons of risk of NSCLC death using competing risk regression.

\section{Findings:}

(1) Older patients have fewer resections of localised NSCLC [adjusted OR 95\% CLs; $80+V s<60$ years; 0.20 $(0.14,0.28)]$. Cases with co-morbidity have fewer resections [adjusted OR, $0.74(0.61,0.90)$ ] and have more conservative resections. Question: Is there the best balance between resection and avoiding surgery to accommodate frailty and co-morbidity?

(2) Compared with public patients, the health insured: have higher odds of localised LC [adjusted OR, 1.23 (1.12, 1.35] and resection for localised NSCLC [adjusted OR, $2.08(1.70,2.54)]$; are more likely to have lobectomies than wedge/segmental resections $(p<0.001)$; and have a lower risk of LC death [adjusted SHR, $0.89(0.85,0.93)]$. Question: Are there opportunities for improving publicpatient outcomes?

(3) Patients born in non-English speaking countries have lower odds of localised disease [adjusted OR, 0.88 (0.79,
0.99)]. - Question: Could this difference be decreased by reducing cultural and language barriers?

(4) Cancers of pulmonary lobes rather than the main bronchus pose lower risks of LC death. Question: Could outcomes for main bronchus cancers be improved by up-skilling or referral to higher-volume centres?

(5) Greater extent of disease is strongly predictive of case fatality - Question: Could LC deaths be reduced by earlier treatment?

(6) Use of lobectomies varies - Question: Could survival be increased through greater use of lobectomies for localised NSCLC?

Conclusions: Linked cancer registry and hospital data can increase system-wide understanding of local health-service delivery and prompt discussion points on how to improve outcomes.

Abbreviations: APDC - Australian Patient Data Collection; CHeReL - Centre for Health Record Linkage; EOD - Extent of Disease; LC - Lung Cancer; NSCLC - Non-Small Cell Cancers; NSWCR - New South Wales Cancer Registry; OR - Relative Odds; SEIFA - Socio-Economic Index for Areas; SES - SocioEconomic Status.

Key words: epidemiology; health service delivery; management. 


\section{David Roder}

Cancer Information and Analysis Unit

Cancer Institute NSW

Alexandria, New South Wales, Australia.

Centre for Population Health Research

University of South Australia

Adelaide, South Australia, Australia.

\section{Hui You}

Cancer Information and Analysis Unit

Cancer Institute NSW

Alexandria, New South Wales, Australia.

\section{Deborah Baker}

Cancer Information and Analysis Unit

Cancer Institute NSW

Alexandria, New South Wales, Australia.

\section{Richard Walton}

Cancer Analysis and Statistics Unit

Cancer Institute NSW

Alexandria, New South Wales, Australia.

\section{Brian McCaughan}

Faculty of Medicine

University of Sydney

Sydney, New South Wales, Australia.

\section{Sanchia Aranda}

School of Health Sciences

University of Melbourne

Melbourne, Victoria, Australia.

Cancer Services and Information (formerly)

Cancer Institute NSW

Alexandria, New South Wales, Australia.

\section{David Currow}

Chief Executive Officer

Cancer Institute NSW

Alexandria, New South Wales, Australia.

\section{Correspondence:}

roder@internode.on.net

\section{Introduction}

Decisions in health service administration ideally are guided by objective evidence of local needs and service performance. Because an evidence gap often applies, varying reliance is placed on anecdotal reports and intuitive judgement. In this study, we explore the utility of linked cancer registry and hospital data to reduce the evidence gap and prompt questions for decision-making.

Lung cancer (LC) is used as a case study because of its importance as the leading cause of cancer death in NSW, Australia and worldwide. [1-3] While prevention through reducing tobacco smoking is the principal public health response, preventive benefits can take many years to materialise. [3] Although a reduction in age-standardised LC incidence and mortality of about $30 \%$ occurred in New South Wales males in the last 25 years, there was a corresponding $133 \%$ increase for females, [1] despite concurrent decreases in tobacco smoking in both sexes. [3] This reflects an extensive lag time. Based on the lag time between smoking decreases and lung cancer mortality reductions in males, female lung cancer mortality is expected to peak soon before beginning to decline. [1] While continued emphasis on reducing tobacco smoking is critically important, supplementary initiatives are needed for more immediate gains, potentially including earlier diagnosis and improved treatment.

Although survival has increased, about $86 \%$ of Australian LC patients still die from their disease within five years of diagnosis. [4] The United States figure is similar at $82 \%$. [5] Risk of death potentially could be reduced by earlier diagnosis. [5-7] Compared with localised cases, the relative risk of death in the five years following diagnosis is about 1.6 for regional and 2.1 for distant stage. [5,7] Unfortunately there is not an accepted population-based screening test. [3] Early United States trial data comparing annual helical computed tomography screening with conventional chest $X$-ray found earlier diagnostic stage and reduced lung cancer mortality for high risk individuals, but confirmatory data are required. [6]

Increased resection could also be beneficial. National Health and Medical Research Council guidelines indicate surgical resection to be the preferred treatment for localised nonsmall cell cancers (NSCLC), as do other guidelines. [8-10] Treatment differences are important when interpreting survival inequalities, but data on extent of disease (EOD) and treatment rarely are available from Australian cancer registries, which complicates interpretation of survival.

New South Wales has the only Australian state registry that routinely records EOD for all solid tumours. Opportunities exist to link NSCLC incidence and death data from the registry to inpatient treatment statistics, using the Centre for Health Record Linkage (CHeReL). The aim of this study is to explore the administrative utility of linked data for investigating associations of system-wide patient and tumour characteristics with: EOD at diagnosis; treatment by resection (localised NSCLC cases); and death from LC. Results are used to raise questions on how to improve health outcomes. 
The extent to which characteristics associated with EOD, resection and LC death represent modifiable causes will need consideration. Nonetheless study results are expected to increase system-wide understanding of local health service delivery and provide an evidence base for guiding discussions on improving service outcomes.

\section{Methods}

LC incidence data for 2003 (Jan) - 2007 (Dec) from the NSW Cancer Registry (NSWCR) and associated death data to December 31, 2008 were linked to surgical resection data for the period from January 2003 to June 2008, extracted from the NSW Admitted Patient Data Collection (APDC). APDC data from July 2000 to June 2008 were also linked to NSWCR data to obtain source data on co-morbidity. Data linkage occurred through $\mathrm{CHeReL}$ using ChoiceMaker probabilistic linkage software. Resections were included if occurring up to six months after diagnosis.

The NSWCR includes population-based registry data, operating under authority of the NSW Public Health Act (1991), which mandates notification by hospitals, pathology laboratories, nursing homes and ancillary sources for invasive cancers (apart from non-melanoma skin cancers) diagnosed in the New South Wales population.
The APDC covers admissions to New South Wales public and private hospitals. NSWCR data were extracted from the registry for the International Classification of Diseases for Oncology (Version 3) (ICD-O-3) C34 topography code but excluding neuroendocrine tumours and non-epithelial cancers, such as soft tissue tumours and sarcomas, fibromatous and myomatous neoplasms. Cancers recorded only on the basis of information from death certification and those first diagnosed at post-mortem were also excluded. [3] In all, 15,014 of 15,498 bronchus and lung cancers on the NSWCR file were included. [3]

Cases were classified by:

- Socio-demographic characteristics - age at diagnosis, sex, country of birth, geographic remoteness of residence, socio-economic status (using the ABS SEIFA (Socio-Economic Index for Areas) relative socio-economic disadvantage index [11]) and Local Health District of residence. The process involved using residential census collection districts to classify by remoteness according to the Australian Standard Geographical Classification (major city, inner regional, outer regional, remote and very remote) and to derive the SEIFA Index of Relative Socio-economic Disadvantage by ABS Statistical Local Area using equal-population quintiles. [11]

Table 1: Relative odds (OR) (95\% confidence limits) of localised extent of disease for lung cancers diagnosed in New South Wales in 2003-2007*

Multivariable logistic regression

\begin{tabular}{|l|c|c|}
\hline CHARACTERISTIC & $\begin{array}{c}\text { NUMBERS (ALL CANCERS/LOCALISED } \\
\text { CANCERS) }\end{array}$ & \\
\hline Age at diagnosis. (yrs.): & & 1.00 \\
$<60$ & $2255 / 565$ & $1.17(1.03,1.33)$ \\
$60-69$ & $3275 / 939$ & $1.34(1.19,1.52)$ \\
$70-79$ & $3927 / 1210$ & $1.61(1.40,1.86)$ \\
$80+$ & $2037 / 667$ & \\
\hline Sex: & & 1.00 \\
Male & $7124 / 2094$ & $1.07(0.98,1.17)$ \\
Female & $4370 / 1287$ & 1.00 \\
\hline Public/private status: & & $1.23(1.12,1.35)$ \\
Public & $7683 / 2153$ & $1.23(0.83,1.81)$ \\
Private (+ Veterans Affairs) & $3636 / 1187$ & \\
Unknown & $175 / 41$ & 1.00 \\
\hline Remoteness (residence): & & $0.96(0.84,1.10)$ \\
Major city & $6523 / 1950$ & $1.08(0.88,1.32)$ \\
Inner regional & $3328 / 925$ & $1.54(1.01,2.35)$ \\
Outer regional & $1505 / 451$ & \\
Remote/very remote & $138 / 55$ & \\
\hline
\end{tabular}


Table 1: Relative odds (OR) (95\% confidence limits) of localised extent of disease for lung cancers diagnosed in New South Wales in 2003-2007* continued

\begin{tabular}{|c|c|c|}
\hline CHARACTERISTIC & $\begin{array}{l}\text { NUMBERS (ALL CANCERS/LOCALISED } \\
\text { CANCERS) }\end{array}$ & ADJUSTED OR ** \\
\hline \multicolumn{3}{|l|}{$\begin{array}{l}\text { SES quintile (SEIFA) } \\
\text { (residence): }\end{array}$} \\
\hline 1 (least disadvantaged) & $1920 / 565$ & 1.00 \\
\hline 2 & $1908 / 547$ & $1.00(0.84,1.19)$ \\
\hline 3 & $2404 / 688$ & $1.04(0.86,1.26)$ \\
\hline 4 & $2807 / 823$ & $1.08(0.89,1.31)$ \\
\hline 5 (most disadvantaged) & $2455 / 758$ & $1.15(0.94,1.40)$ \\
\hline \multicolumn{3}{|l|}{ Country of birth: } \\
\hline Australia & $7493 / 2223$ & 1.00 \\
\hline Other-English speaking & $1431 / 396$ & $0.93(0.81,1.06)$ \\
\hline Other-not English speaking & $2395 / 674$ & $0.88(0.79,0.99)$ \\
\hline Unknown & $175 / 88$ & $2.56(1.86,3.52)$ \\
\hline \multicolumn{3}{|l|}{ Lung location: } \\
\hline C340 (main bronchus) & $1057 / 294$ & 1.00 \\
\hline C341 (upper lobe) & $4269 / 1502$ & $1.48(1.27,1.72)$ \\
\hline C342 (middle lobe) & $480 / 191$ & $1.81(1.43,2.28)$ \\
\hline C343 (lower lobe) & $2368 / 904$ & $1.63(1.38,1.92)$ \\
\hline C348 (overlapping) & $125 / 35$ & $1.03(0.67,1.56)$ \\
\hline C349 (not specified) & $3195 / 455$ & $0.45(0.38,0.54)$ \\
\hline \multicolumn{3}{|l|}{ Histology type: } \\
\hline Adenocarcinoma & $3711 / 1014$ & 1.00 \\
\hline Squamous cell carcinoma & $2020 / 890$ & $1.93(1.71,2.18)$ \\
\hline Large cell carcinoma & $3740 / 910$ & $0.89(0.80,0.99)$ \\
\hline Other/unknown & $2023 / 567$ & $1.16(1.02,1.32)$ \\
\hline \multicolumn{3}{|l|}{ Charlson co-morbidity score: } \\
\hline 0 & $4639 / 1430$ & 1.00 \\
\hline $1+$ & $5687 / 1686$ & $0.96(0.87,1.05)$ \\
\hline Unknown & $1168 / 265$ & $0.71(0.60,0.83)$ \\
\hline
\end{tabular}

*Data source: NSW Cancer Registry; ${ }^{* *}$ Adjusted for other variables in the Table1(and Local Health District of residence). Note: Excludes cases with unknown extent of disease.

- Histology type - adenocarcinoma, squamous cell carcinoma, large cell carcinoma, and other types, as classified by ICD-O-3. [12]

- Location of tumour - main bronchus and upper, middle and lower pulmonary lobes. [12]

- EOD - localised, regional and distant. [12]

- Resection type - wedge, segmental, lobectomy and pneumonectomy. [12]

- Co-morbidity - Charlson index derived from APDC data for up to five years before LC diagnosis. [13]

- Payment status - public or private (or Veterans coverage) for the payment status applying at the first hospital episode for the index cancer.
- Emergency attendance - as indicated by the urgency of admission flag for admission where treatment was required within 24 hours.

NSWCR and APDC data were linked by CHeReL using probabilistic linkage and identifiers removed before release for analysis. Research ethics approval was obtained [NSW Population and Health Services Research Ethics Committee Reference No. 2009/04/150].

Multiple logistic regression analysis was used to calculate relative odds (odds ratios) of localised compared with more advanced EOD at diagnosis (Table 1), and treatment of localised cases by resection (Figure 1) and resection type, adjusting for socio-demographic and clinical factors. [14] Multivariable competing risk regression was used to calculate 
Figure 1: Relative odds $(95 \% \mathrm{Cl})$ of resection for localized non-small cell lung cancer diagnosed in New South Wales in $2003-2007^{*}$

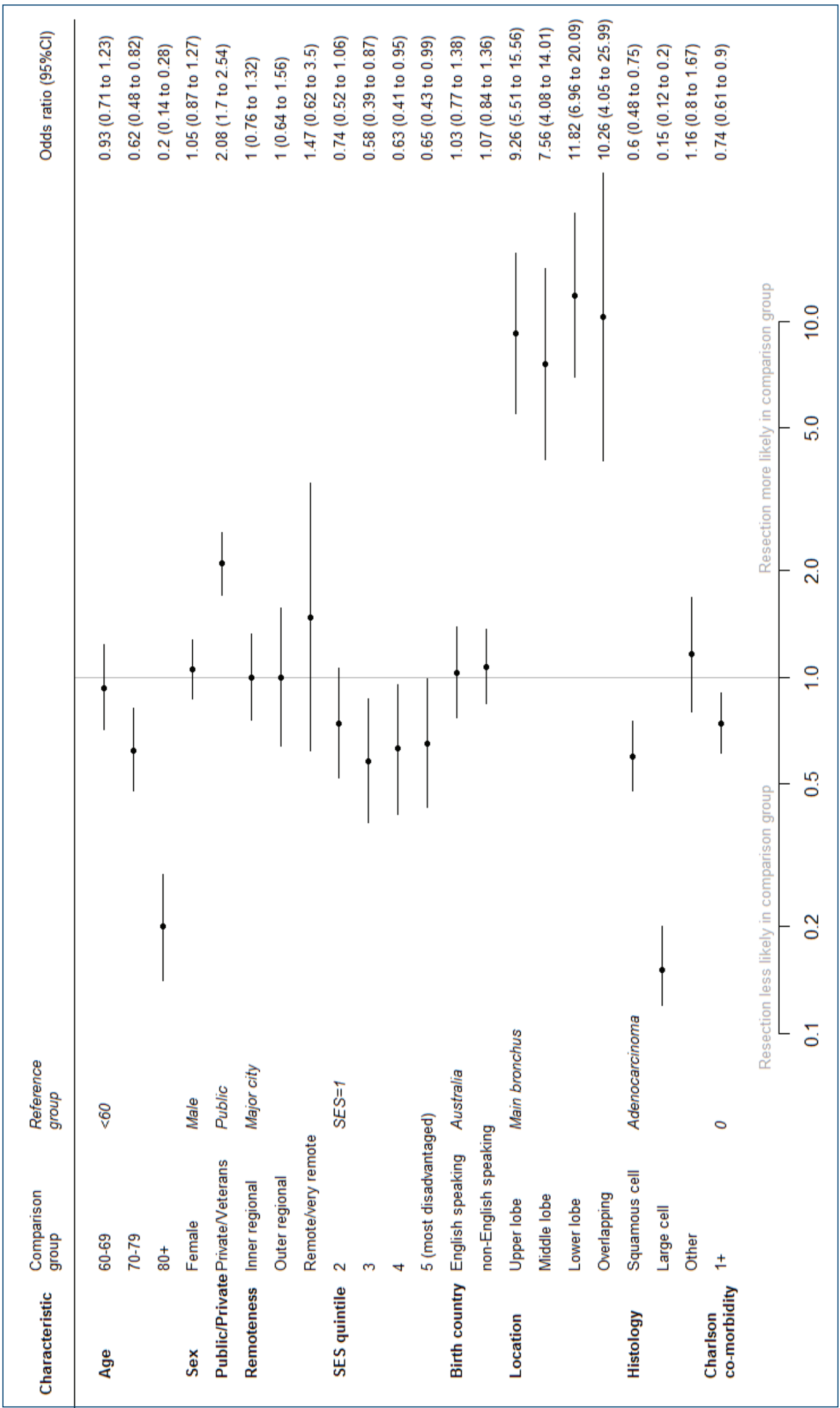


sub-hazards ratios for LC death from time of diagnosis to death (in months) or December 31, 2008, whichever came first, with deaths from other causes as the competing event. [14] Co-linearity assumptions were checked and log-normal plots examined to test proportionality.

Cases with unknown extent of disease (24.2\% of cases) were excluded from logistic regression models comparing localised with more advanced EOD, but were included as a dummy variable in competing risk regression models when deriving sub-hazards ratios for LC death. Missing values for other independent variables were also included as dummy variables. When results of logistic regression and competing risk regression were checked using complete case analysis that excluded cases with missing values, findings were similar. STATA release 12 was used. [14]

\section{Results}

\section{By socio-demographic characteristic Age at diagnosis}

Odds of localised EOD were higher for older ages (Table 1). Older cases with localised NSCLC had fewer resections (Figure 1).Compared with those under 60 years, the adjusted relative odds of resection $(95 \% \mathrm{CLs})$ were $0.62(0.48,0.82)$ and $0.20(0.14,0.28)$ for $70-79$ and $80+$ year olds respectively. Surgery also tended to be more conservative $(p=0.051)$, the ratio of lobectomies to wedge resections decreasing from 8.5 to 1 for cases less than 60 years to 4.9 to 1 for those aged 80 years or more. The corresponding ratio of lobectomies to wedge and segmental resections decreased from 2.2 to 1 to 1.8 to 1 . The older the age, the higher was the risk of LC death (Table 2).

\section{Sex}

Females had more conservative resections, the ratio of lobectomies to wedge resections being 5.7 to 1 for females compared with 8.7 to 1 for males $(p=0.050)$. The corresponding ratio of lobectomies to wedge and segmental resections was 1.7 to 1 and 2.2 to 1 respectively. Female patients had a lower risk of LC death (Table 2).

\section{Payment status}

Patients with private health insurance (or Veterans coverage) had higher odds of localised EOD (Table 1 ) and compared with public patients, adjusted relative odds of resection for localised NSCLC of $2.08(1.70,2.54)$ (Figure 1). They also had higher odds of lobectomy compared with wedge resection of 15.8 to 1 compared with 4.6 to 1 for public patients $(p<0.001)$, and of lobectomy compared with wedge and segmental resections, of 3.2 to 1 and 1.4 to 1 respectively $(p<0.001)$. The risk of LC death was lower in insured patients (Table 2).

\section{Remoteness}

An unexpected $54 \%$ elevation in odds of localised EOD occurred at presentation for residents from remote/very remote compared with major city areas after adjustment (Table 1). Odds of resection from localised NSCLC did not vary by remoteness (Figure 1), nor did types ( $p>0.200$ ), as indicated by the ratio of lobectomies to wedge resections $(p=0.329)$ and to wedge and segmental resections $(p=0.549)$. Elevated risk of LC death in inner and outer regional than major city areas did not persist after co-variable adjustment (Table 2). Risk of LC death was not elevated in remote/very remote areas.

\section{Socio-economic status (SES)}

Adjusted relative odds of resection for localised NSCLC were lower at $0.58(0.39,0.87), 0.63(0.41,0.95)$ and $0.65(0.43$, 0.99 ) for lower quintiles three, four and five respectively compared with quintile one (highest SES) (Figure 1), but resection types did not vary by quintile $(p=0.233)$. SES was not associated with risk of LC death (Table 2 ).

\section{Country of birth}

Adjusted analysis indicated lower odds of localised disease for patients with non-English speaking than Australian country of birth (Table 1) and lower risk of LC death (Table 2). Resection types did not differ by country of birth $(p=0.275)$.

\section{By co-morbidity status}

Cases with co-morbidity (Charlson score 1+Vs 0 ) had lower adjusted odds of resection than other patients for localised NSCLC at $0.74(0.61,0.90)$ (Figure 1). The lobectomy to wedge resection ratios was 2.2 to 1 and 4.6 to 1 respectively, and the lobectomy to wedge and segmental resection ratios was 1.7 to 1 and 2.3 to 1 respectively. Higher co-morbidity was associated with higher risk of LC death which persisted, although more marginal, in multivariable models (Table 2).

\section{By clinical characteristics \\ Location}

Cancers of pulmonary lobes had higher odds of localised EOD than cancers of the main bronchus (Table 1). Higher adjusted relative odds of resection applied for localised NSCLC of the pulmonary lobes at 9.26 (5.51, 15.56), 7.56 $(4.08,14.01)$ and $11.82(6.96,20.09)$ respectively, compared with cancers of the main bronchus (Figure 1), but with little difference in resection types $(p=0.820)$. Risk of $L C$ death was lower for LC in pulmonary lobes than the main bronchus (Table 2).

\section{Histology type}

Compared with adenocarcinomas, squamous cell lesions had higher and large cell lesions lower odds of localised EOD 
Table 2: Sub-hazard ratios (SHR) (95\% confidence limits) for cumulative probability of death from lung cancer among New South Wales cases diagnosed in 2003-2007, according to patient and cancer characteristics, and treatment by resection*

\section{Competing risk regression}

\begin{tabular}{|c|c|c|c|c|c|}
\hline CHARACTERISTIC & $\begin{array}{c}\text { NUMBERS } \\
\text { (CASES/LUNG } \\
\text { CANCER DEATHS) }\end{array}$ & $\begin{array}{l}\text { UNADJUSTED } \\
\text { SHR }\end{array}$ & $\begin{array}{l}\text { ADJUSTED } \\
\text { SHR }^{* *}\end{array}$ & $\begin{array}{l}\text { ADJUSTED } \\
\text { SHR }^{* * *}\end{array}$ & $\begin{array}{l}\text { ADJUSTED } \\
\text { SHR }^{* * * *}\end{array}$ \\
\hline \multicolumn{6}{|l|}{ Age at diagnosis (yrs.): } \\
\hline$<60$ & $2710 / 1874$ & 1.00 & 1.00 & 1.00 & 1.00 \\
\hline $60-69$ & $4047 / 2861$ & $1.07(1.02,1.13)$ & $1.07(1.01,1.13)$ & $1.12(1.06,1.18)$ & $1.11(1.05,1.17)$ \\
\hline $70-79$ & $5232 / 3951$ & $1.28(1.21,1.35)$ & $1.24(1.17,1.30)$ & $1.36(1.29,1.44)$ & $1.32(1.25,1.39)$ \\
\hline $80+$ & $3025 / 2396$ & $1.59(1.50,1.68)$ & $1.48(1.39,1.57)$ & $1.72(1.61,1.83)$ & $1.57(1.47,1.67)$ \\
\hline \multicolumn{6}{|l|}{ Sex: } \\
\hline Male & $9374 / 7012$ & 1.00 & 1.00 & 1.00 & 1.00 \\
\hline Female & $5640 / 4070$ & $0.91(0.88,0.94)$ & $0.91(0.87,0.95)$ & $0.91(0.87,0.94)$ & $0.92(0.88,0.95)$ \\
\hline \multicolumn{6}{|l|}{ Public/private status: } \\
\hline Public & $9891 / 7526$ & 1.00 & 1.00 & 1.00 & 1.00 \\
\hline Private (+ Veterans Affairs) & $4792 / 3369$ & $0.84(0.81,0.87)$ & $0.81(0.77,0.84)$ & $0.84(0.81,0.88)$ & $0.89(0.85,0.93)$ \\
\hline Unknown & $331 / 187$ & $0.64(0.55,0.74)$ & $0.75(0.64,0.88)$ & $0.82(0.70,0.96)$ & $0.75(0.64,0.88)$ \\
\hline \multicolumn{6}{|l|}{ Remoteness (residence): } \\
\hline Major city & $8439 / 6164$ & 1.00 & 1.00 & 1.00 & 1.00 \\
\hline Inner regional & $4425 / 3315$ & $1.07(1.03,1.12)$ & $0.99(0.93,1.04)$ & $0.99(0.93,1.05)$ & $0.98(0.93,1.04)$ \\
\hline Outer regional & $1943 / 1459$ & $1.09(1.03,1.15)$ & $0.96(0.88,1.05)$ & $0.98(0.89,1.07)$ & $0.95(0.87,1.04)$ \\
\hline Remote/very remote & $207 / 144$ & $0.94(0.80,1.10)$ & $0.84(0.69,1.02)$ & $0.89(0.74,1.07)$ & $0.89(0.74,1.07)$ \\
\hline \multicolumn{6}{|l|}{$\begin{array}{l}\text { SES quintile (SEIFA) } \\
\text { (residence): }\end{array}$} \\
\hline 1 (least disadvantaged) & $2403 / 1716$ & 1.00 & 1.00 & 1.00 & 1.00 \\
\hline 2 & $2486 / 1810$ & $1.05(0.98,1.11)$ & $1.04(0.96,1.12)$ & $1.04(0.96,1.13)$ & $1.04(0.96,1.12)$ \\
\hline 3 & $3206 / 2391$ & $1.11(1.05,1.18)$ & $1.02(0.93 .1 .11)$ & $1.04(0.96,1.14)$ & $1.03(0.95,1.13)$ \\
\hline 4 & $3698 / 2768$ & $1.12(1.06,1.18)$ & $1.01(0.92,1.10)$ & $1.03(0.94,1.13)$ & $1.02(0.93,1.12)$ \\
\hline 5 (most disadvantaged) & $3221 / 2397$ & $1.09(1.03,1.16)$ & $1.06(0.97,1.16)$ & $1.07(0.97,1.17)$ & $1.06(0.97,1.16)$ \\
\hline \multicolumn{6}{|l|}{ Country of birth: } \\
\hline Australia & $9796 / 7369$ & 1.00 & 1.00 & 1.00 & 1.00 \\
\hline Other-English speaking & $1853 / 1408$ & $1.02(0.96,1.07)$ & $1.00(0.94,1.05)$ & $0.98(0.92,1.03)$ & $0.98(0.92,1.04)$ \\
\hline Other-not English speaking & $3029 / 2203$ & $0.90(0.86,0.94)$ & $0.91(0.87,0.96)$ & $0.88(0.84,0.92)$ & $0.88(0.84,0.93)$ \\
\hline Unknown & $336 / 102$ & $0.30(0.24,0.36)$ & $0.31(0.25,0.38)$ & $0.36(0.29,0.45)$ & $0.39(0.31,0.48)$ \\
\hline \multicolumn{6}{|l|}{ Lung location: } \\
\hline C340 (main bronchus) & $1315 / 1112$ & 1.00 & 1.00 & 1.00 & 1.00 \\
\hline C341 (upper lobe) & $5446 / 3718$ & $0.61(0.58,0.65)$ & $0.64(0.60,0.68)$ & $0.68(0.64,0.73)$ & $0.78(0.73,0.84)$ \\
\hline C342 (middle lobe) & $614 / 408$ & $0.59(0.53,0.66)$ & $0.60(0.54,0.67)$ & $0.66(0.59,0.73)$ & $0.75(0.67,0.84)$ \\
\hline C343 (lower lobe) & $2991 / 2035$ & $0.61(0.57,0.66)$ & $0.64(0.60,0.69)$ & $0.70(0.65,0.75)$ & $0.83(0.77,0.89)$ \\
\hline C348 (overlapping) & $143 / 98$ & $0.66(0.53,0.81)$ & $0.66(0.53,0.83)$ & $0.69(0.54,0.87)$ & $1.00(0.80,1.26)$ \\
\hline C349 (not specified) & $4505 / 3711$ & $1.04(0.97,1.10)$ & $1.01(0.94,1.08)$ & $0.89(0.83,0.95)$ & $0.93(0.87,1.00)$ \\
\hline \multicolumn{6}{|l|}{ Histology type: } \\
\hline Adenocarcinoma & $4394 / 2954$ & 1.00 & 1.00 & 1.00 & 1.00 \\
\hline Squamous cell carcinoma & $2645 / 1776$ & $0.98(0.92,1.03)$ & $0.91(0.86,0.96)$ & $1.06(1.00,1.13)$ & $1.05(0.99 .1 .11)$ \\
\hline Large cell carcinoma & $5230 / 4274$ & $1.59(1.51,1.66)$ & $1.39(1.33,1.46)$ & $1.43(1.37,1.50)$ & $1.27(1.21,1.34)$ \\
\hline Other/unknown & $2745 / 2078$ & $1.31(1.24,1.38)$ & $1.44(1.08,1.21)$ & $1.16(1.09,1.23)$ & $1.04(0.98,1.10)$ \\
\hline
\end{tabular}


Table 2: Sub-hazard ratios (SHR) (95\% confidence limits) for cumulative probability of death from lung cancer among New South Wales cases diagnosed in 2003-2007 continued

\begin{tabular}{|c|c|c|c|c|c|}
\hline CHARACTERISTIC & $\begin{array}{c}\text { NUMBERS } \\
\text { (CASES/LUNG } \\
\text { CANCER DEATHS) }\end{array}$ & $\begin{array}{l}\text { UNADJUSTED } \\
\text { SHR }\end{array}$ & $\begin{array}{l}\text { ADJUSTED } \\
\text { SHR*** }\end{array}$ & $\begin{array}{l}\text { ADJUSTED } \\
\text { SHR }^{* * *}\end{array}$ & $\begin{array}{l}\text { ADJUSTED } \\
\text { SHR }^{* * * * *}\end{array}$ \\
\hline \multicolumn{6}{|c|}{$\begin{array}{l}\text { Charlson co-morbidity } \\
\text { score: }\end{array}$} \\
\hline 0 & $5740 / 4149$ & 1.00 & 1.00 & 1.00 & 1.00 \\
\hline $1+$ & $7420 / 5586$ & $1.20(1.16,1.25)$ & $1.05(1.01,1.10)$ & $1.05(1.01,1.09)$ & $1.03(0.99,1.08)$ \\
\hline Unknown & $1854 / 1347$ & $0.95(0.90,1.00)$ & $0.93(0.88,0.99)$ & $0.95(0.90,1.01)$ & $0.95(0.90,1.01)$ \\
\hline \multicolumn{6}{|l|}{ Extent of disease: } \\
\hline Localised & $3381 / 1785$ & 1.00 & & 1.00 & 1.00 \\
\hline Regional & $2475 / 1645$ & $1.45(1.36,1.54)$ & & $1.48(1.38,1.58)$ & $1.44(1.34,1.54)$ \\
\hline Distant & $5638 / 5122$ & $3.42(3.24,3.62)$ & & 3.18 (3.00. 3.37) & $2.39(2.25,2.53)$ \\
\hline Unknown & $3520 / 2530$ & $1.62(1.53,1.72)$ & & $1.39(1.31,1.48)$ & $1.05(0.99,1.12)$ \\
\hline \multicolumn{6}{|l|}{ Resection: } \\
\hline None & $12774 / 10420$ & $5.66(5.14,6.22)$ & $3.94(3.57,4.35)$ & & \\
\hline Segmental & $462 / 111$ & $0.87(0.72,1.07)$ & $0.86(0.70,1.04)$ & & \\
\hline Wedge & $190 / 68$ & $1.36(1.08,1.72)$ & $1.29(1.03,1.63)$ & & \\
\hline Lobectomy & $1384 / 380$ & 1.00 & 1.00 & & \\
\hline Pneumonectomy & $204 / 103$ & $1.95(1.62,2.35)$ & $1.64(1.35,1.98$ & & \\
\hline
\end{tabular}

*Data source: NSW Cancer Registry; **Adjusted for other variables in Table 2 (+ Local Health District of residence) (except extent of disease and resection); ${ }^{* * * A d j u s t e d ~ f o r ~ o t h e r ~ v a r i a b l e s ~ i n ~ T a b l e ~} 2$ (+ Local Health District of residence) (except resection);

**** Adjusted for all other variables in Table 2 (+ Local Health District of residence)

(Table 1). Also compared with adenocarcinomas, squamous cell and large cell carcinomas had fewer resections for localised NSCLC, with adjusted relative odds of $0.60(0.48$, $0.75)$ and $0.15(0.12,0.20)$ respectively (Figure 1$)$, but resection type did not vary $(p=0.373)$. Case fatality was elevated for large cell carcinomas (Table 2).

\section{EOD}

Cases with regional and distant spread had higher risk of LC death than localised cases (Table 2).

\section{Resection type}

Risks of LC death were highest for non-resected cases (Table 2). Compared with lobectomy cases, risk of LC death was higher for those having a pneumonectomy or wedge resection. Statistically significant differences were not evident between cases having lobectomies and segmental resections (adjusted SHR for segmental resection=0.92 $(0.72,1.19))$ (Table 3).

\section{By service characteristics (resection cases/localised and regional EOD only) \\ Emergency presentation}

Cases presenting as an emergency at time of diagnosis had an elevated risk of LC death but this could have occurred by chance (adjusted SHR=1.09 $(0.60,1.97)$ ) (Table 3).

\section{Time from diagnosis to surgery}

Unadjusted analysis indicated higher case fatality with longer time to surgery, but the adjusted model did not indicate a significant difference (Table 3).

\section{Hospital resection volume}

While SHRs were lower when numbers of lung resections were in the top two of three volume categories, confidence intervals encompassed 1.00 and differences were attributable to chance (Table 3).

\section{Discussion}

NSWCR and administrative data provide similar statistical profiles for LC to international research evidence, lending credibility to findings. They include lower odds of surgical resection of localised NSCLC for older people and use of more conservative resection types, likely reflecting accommodations for reduced physiological capacity. [18] Older people also had a higher case fatality from LC, probably due to higher levels of co-morbidity and frailty and lower resection rates for localised NSCLC. [18] 
Table 3: Sub-hazard ratios (SHR) (95\% confidence limits) for cumulative probability of death from lung cancer among non-small cell cases diagnosed with localised or regional extent of disease in New South Wales in 2003-2007 and treated by resection within six months of diagnosis*

\section{Competing risk regression}

\begin{tabular}{|c|c|c|c|}
\hline CHARACTERISTIC & $\begin{array}{l}\text { NUMBERS (CASES/LUNG } \\
\text { CANCER DEATHS) }\end{array}$ & UNADJUSTED SHR & ADJUSTED SHR** \\
\hline \multicolumn{4}{|l|}{ Extent of disease: } \\
\hline Localised & $1168 / 213$ & 1.00 & 1.00 \\
\hline Regional & $766 / 312$ & $2.71(2.28,3.22)$ & $2.52(2.09,3.03)$ \\
\hline \multicolumn{4}{|l|}{ Resection type: } \\
\hline Segmental & $395 / 85$ & $0.84(0.66,1.06)$ & $0.92(0.72,1.19)$ \\
\hline Wedge & $146 / 48$ & $1.44(1.07,1.93)$ & $1.60(1.17,2.21)$ \\
\hline Lobectomy & $1222 / 310$ & 1.00 & 1.00 \\
\hline Pneumonectomy & $171 / 82$ & $2.08(1.64,2.64)$ & $1.57(1.19,2.09)$ \\
\hline \multicolumn{4}{|c|}{ Emergency attendance: } \\
\hline No & $1889 / 511$ & 1.00 & 1.00 \\
\hline Yes & $45 / 14$ & $1.09(0.63,1.86)$ & $1.09(0.60,1.97)$ \\
\hline \multicolumn{4}{|c|}{$\begin{array}{l}\text { Time from diagnosis to } \\
\text { resection (months): }\end{array}$} \\
\hline$<1$ & $844 / 200$ & 1.00 & 1.00 \\
\hline $1-2$ & $915 / 264$ & $1.23(1.02,1.47)$ & $1.02(0.84,1.24)$ \\
\hline $3-6$ & $175 / 61$ & $1.60(1.20,2.13)$ & $1.12(0.81,1.55)$ \\
\hline \multicolumn{4}{|c|}{$\begin{array}{l}\text { Hospital resection volume } \\
\text { per year: }\end{array}$} \\
\hline$<16$ & $626 / 178$ & 1.00 & 1.00 \\
\hline $16-55$ & $671 / 179$ & $0.92(0.75,1.13)$ & $0.87(0.70,1.07)$ \\
\hline$>55$ & $637 / 168$ & $0.90(0.73,1.11)$ & $0.87(0.68,1.12)$ \\
\hline
\end{tabular}

*Data source: NSW Cancer Registry

**Adjusted for: other variables in Table 3, age at diagnosis; sex; public/private status; remoteness of residence; SES quintile; Local Health District of residence; country of birth; lung location of cancer; histology type; and Charlson co-morbidity

The lower EOD at diagnosis in older patients is contrary to patterns seen for many cancers, [15] but accords with results of earlier United States lung studies. $[16,17]$ While reasons are unknown, it could reflect earlier detection from regular medical attention for tobacco-related respiratory and other comorbidity in older people. Also, less intensive diagnostic investigation of older cases may have led to under detection of more distant disease.

More conservative resections and risk of LC death applied for females than males for localised NSCLC, as reported in other studies. $[19,20]$ Although this was not explained by differences in modelled variables, the measure of comorbidity was blunt and residual confounding from higher levels of tobacco-induced and other co-morbidity could have led to an artificial elevation of deaths in males. [3]
Private health insurance was associated with more localised EOD, which may reflect higher SES. Higher SES Danish lung cancer cases have also shown higher odds of more localised EOD. [21] New South Wales patients with private insurance had higher odds of resection for localised NSCLC and were more likely to have a lobectomy than more conservative wedge or segmental resections. Similar results have been reported for NSCLC in North America. [22] The privately insured also had a lower risk of LC death which accords with North American evidence. [23] Statistical modelling indicated that this was not explained in New South Wales by more localised EOD at diagnosis, higher resection rates for localised NSCLC or a higher ratio of lobectomies to conservative procedures among the privately insured. 
The presence of more advanced EOD at diagnosis among patients born in non-English speaking countries was a novel finding. BreastScreen data show that women from culturally and linguistically diverse backgrounds have lower screening participation. [24] This may be part of a broader pattern where cultural and language barriers reduce or delay use of diagnostic and related health services.

Despite this difference, patients born in non-English speaking countries had a lower recorded risk of LC death than the Australian born. This may be due to a greater residential proximity to specialist treatment centres in major cities or alternatively a healthy migrant effect. It is also possible that underrecording of deaths could occur if significant numbers returned to birth countries in the terminal stages of their disease, such that their deaths were not recorded in Australia.

Reasons for earlier EOD in remote/very remote areas are not known and run counter to data for other populations. [25] Lower access to specialised diagnostic services in these areas may have reduced detection of more advanced disease. An elevation in case fatality was not suggested in remote/very remote regions, which accords with a study of United States Medicare data. [26]

Resection rates for localised NSCLC were lower for lower than upper SES groups in New South Wales, as observed in other populations, [27] potentially due to more limited service access. While United States research has indicated lower survivals in lower SES groups, [27] poorer survivals were not indicated in lower SES areas of New South Wales in multivariable analyses.

Patients with higher co-morbidity had fewer resections for localised NSCLC and their resections were more conservative, as found in other populations. [21] This may reflect attempts to avoid undue surgical risk. It was anticipated that comorbidity would be predictive of risk of LC death, [28] but only a weak relationship was observed, potentially due to the bluntness of the co-morbidity measure.

Cancers of pulmonary lobes had higher odds of localised EOD than cancers of the main bronchus, possibly reflecting greater visibility in imaging. Higher odds of resection for localised NSCLC presented for those located in pulmonary lobes than the main bronchus where more extensive and complex surgery may carry greater risks, especially for patients with low cardiopulmonary reserve. [29] Risk of LC death was lower for pulmonary lobe lesions than for those in the main bronchus, as reported elsewhere. [29]
Compared with adenocarcinomas, squamous cell lesions had higher odds and large cell lesions lower odds of localised EOD. Squamous cell and large-cell lesions were less likely to be treated by resection. Squamous cell carcinomas are often located centrally where surgery may be more difficult. [29] Risk of LC death was highest for large cell carcinomas, likely due to more aggressive biology. [29] Predictably, advanced EOD was strongly predictive of risk of LC death. For resection cases with localised or regional disease, a higher risk of LC death with longer time to surgery was evident in the unadjusted analysis, but not after co-variable adjustment.

The highest case fatality applied to non-resected cases. This may reflect a causal association for localised NSCLC, but also residual confounding. Compared with those having a lobectomy, risk of LC death following wedge resection was higher. Lobectomy would often be the surgery type of choice in treatments of localised NSCLC with curative intent, [8-10] which may explain the better outcomes for lobectomy cases. The lack of a significant difference in outcomes between lobectomies and segmental resections is consistent with earlier United States findings for early EOD NSCLC. [30,31]

While risk of LC death was lower when hospital numbers for lung resections were in the top two of three volume categories, differences were in the range attributable to chance. Further investigation is needed into relationships between surgical volume within resection types and by subgroup of patients.

The present data are observational, not experimental, and sometimes of sub-optimal quality, as seen for co-morbidity. Nonetheless findings generally accord with the international evidence, which adds to their credibility in the New South Wales setting. The potential for these relationships to be causal and modifiable needs to be considered by the clinical community, along with relevant interventions.

Example questions arising from the present study include:

(1) Is the best balance being achieved between resection and non-resection to accommodate age-related frailty and co-morbidity?

(2) Are there modifiable causal factors for improving survival outcomes for public patients?

(3) Could more advanced EOD in patients born in nonEnglish speaking countries be decreased by reducing cultural and language barriers to services?

(4) Is the best balance being achieved between optimal therapy and accommodations for co-morbidity? 
(5) Could the higher risk of LC death for cancers of the main bronchus be reduced by up-skilling or referral to highervolume centres?

(6) Do opportunities exist for earlier treatment to increase survival? (7) Could survivals be increased through greater use of lobectomies? (8) Are segmental resections an effective substitute for lobectomies for some patients?

\section{Conclusions}

Linked registry and administrative data can increase systemwide understanding of health service delivery and outcomes. They prompt questions that could be workshopped with a view to achieving better outcomes. Linked data can provide useful input for administrative decision-making.

\section{Competing interests}

The authors declare that they have no competing interests.

\section{References}

1. NSW cancer registry statistical reporting [accessed 2015 Jan 15]. Sydney: Cancer Institute NSW; 2014. Available from: http://www. statistics.cancerinstitute.org.au

2. Ferlay J, Bray F, Pisani P, Parkin DM. GLOBOCAN 2002. Cancer incidence, mortality and prevalence worldwide IARC CancerBase No. 5 [Internet]. Version 2.0 [accessed 2014, Nov]. Lyon: IARC Press; 2004.Available from: http://www-dep.iarc.fr/.

3. Australian Institute of Health and Welfare and Cancer Australia. Lung cancer in Australia: an overview [accessed 2015, Jan]. Cancer Series no. 64. Cat. No. CAN 58. Canberra: AlHW; 2011. Available from: <http://www.aihw.gov.au/publication-detail/?id= 10737420419>.

4. Australian Institute of Health and Welfare. Cancer survival and prevalence in Australia: period estimates from 1982 to 2010. Cancer series no. 69. Cat. no. CAN 65. Canberra: AlHW; 2012.

5. Howlader N, Noone AM, Krapcho M et al, editors. SEER Cancer Statistics Review, 1975-2011. Bethesda, MD: National Cancer Institute.. Available at http://seer.cancer.gov/csr/1975_2011/, based on November 2013 SEER data submission, posted to the SEER web site, 2014, April.

6. Aberle DR, Adams AM, Berg CD et al. Reduced lung-cancer mortality with low-dose computed tomographic screening. N Engl J Med. 2011;365(5):395-409.

7. Walters $S$, Maringe $C$, Coleman MP et al. Lung cancer survival and stage at diagnosis in Australia, Canada, Denmark, Norway, Sweden and the UK: a population-based study, 2004-2007. Thorax. 2013; 68(6):551-64.

8. Cancer Council Australia and Australian Cancer Network (approved by NHMRC). Clinical practice guidelines for the prevention, diagnosis and management of lung cancer. Sydney: Cancer Council Australia; 2004. Available from: http://www.nhmrc.gov.au/_files_ nhmrc/publications/attachments/cp97.pdf

9. National Comprehensive Cancer Network (NCCN). Clinical Practice Guidelines in Oncology, Non Small Cell Lung Cancer, Version 3.2011 [accessed 2014, Nov]. Available from: www.nccn.com.

10. Scott WJ, Howington J, Feigenberg S, et al. Treatment of non-small cell lung cancer Stage I and stage II: ACCP Evidence Bases Clinical Practice Guidelines (2nd ed). Chest. 2007;132(3): 234S-242S.

11. Australian Institute of Health and Welfare, Cancer Australia and Australasian Association of Cancer Registries. Cancer survival and prevalence in Australia: cancers diagnosed from 1982 to 2004. Cancer Series no. 42. Cat. No. CAN 38. Canberra: AlHW; 2008.
12. Hutchison $\mathrm{CL}$, Menck HR, Burch $\mathrm{M}$, et al, editors. Cancer registry management principles and practice. 2nd ed. Springfield, Illinois: National Cancer Registrars Association; 2004.

13. Charlson ME, Pompei $P$, Ales KL, et al. A new method of classifying prognostic comorbidity in longitudinal studies: development and validation. J Chron Dis. 1987;40(5):373-383.

14. StataCorp. STATA Statistical Software. Release 12. College Station, Texas: StataCorp LP, 2013.

15. Lyratzopoulos G, Abel GA, Brown CH, et al. Socio-demographic inequalities in stage of cancer diagnosis: evidence from patients with female breast, lung, colon, rectal, prostate, renal, bladder, melanoma, ovarian and endometrial cancer. Ann Oncol. 2013; 24(3):843-50.

16. O'Rourke MA, Feussner JR, Feigl P, et al. Age trends of lung cancer stage at diagnosis: implications for lung cancer screening in the elderly. JAMA. 1987;258(7):921-6.

17. Ramalingam S, Pawlish K, Gadgeel S, et al. Lung cancer in young patients: analysis of a Surveillance, Epidemiology, and End Results database. J Clin Oncol. 1998;16:651-7.

18. Ng R, de Boer R, Green MD. Undertreatment of elderly patients with non-small-cell lung cancer. Clin Lung Cancer. 2005;7(3):168-74.

19. De Perrot $M$, Licker $M$, Bouchardy $C$, et al. Sex differences in presentation, management, and prognosis of patients with nonsmall cell lung carcinoma. J Thoracic Cardiovasc Surg. 2000; 119(1):21-6.

20. Nakamura H, Ando K, Shinmyo T, et al. Female gender is an independent prognostic factor in non-smallcell lung cancer: a meta-analysis. Ann Thorac Cardiovasc Surg. 2010;17(5):469-80.

21. Dalton $S A$, Frederiksen $B L$, Jacobsen $E$, et al. Socioeconomic position, stage of lung cancer and time between referral and diagnosis in Denmark, 2001-2008. Br J Cancer. 2011;105(7):1042-8.

22. Groth SS, Al-Refaie WB, Zhong W, et al. Effect of insurance status on surgical treatment of early-stage non-small cell lung cancer. Ann Thorac Surg. 2013;95(4):1221-6.

23. Xiaolong N, Roche LM, Pawlish KS, et al. Cancer survival disparities by health insurance status. Cancer Medicine. 2013;2(3):403-11.

24. Australian Institute of Health and Welfare. BreastScreen Australia monitoring report 2012-2013 [accessed 2016, Jan]. Cancer series no. 95. Cat. No. CAN 93. Canberra: AlHW; 2015 (Supplementary table S1.11). Available from <http://www.aihw.gov.au/publicationdetail/?id=60129552866>.

25. Campbell NC, Elliott AM, Sharp L, et al. Rural and urban differences in stage at diagnosis of colorectal and lung cancers. Brit J Cancer. 2001;84(7):910-4.

26. Shugarman LR, Sorbero MES, Tian $\mathrm{H}$, et al. An exploration of urban rural differences in lung cancer survival among Medicare beneficiaries. Am J Pub Health. 2008;98(7):1280-7.

27. Greenwald HP, Polissar NL, Borgatta EF et al. Social factors, treatment, and survival in early-stage nonsmall cell lung cancer. Am J Public Health. 1998;88(11):1681-4.

28. Little AG, Rusch VW, Bonner JA, et al. Patterns of surgical care of lung cancer patients. Ann Thorac Surg. 2005;80(6):2051-6.

29. Strand TE, Rostad $\mathrm{H}$, Moller $\mathrm{B}$ et al. Survival after resection for primary lung cancer: a population based study of 3211 resected patients. Thorax. 2006;61(8):710-5.

30. Ginsberg RJ, Rubinstein LV \& Lung Cancer Study Group Randomized trial of lobectomy versus limited resection for T1 N0 non-small cell lung cancer. Ann Thorac Surg. 1995;60(3):615-23.

31. Warren WH, Faber LP. Segmentectomy versus lobectomy in patients with stage 1 pulmonary carcinoma: Five-year survival and patterns of intrathoracic recurrence. J Thorac Cardiovasc Surg. 1994; 107:1087-94 